\title{
Role of Spirometry in Early Diagnosis of COPD among Smokers
}

\author{
Md. Ansar Ali, ${ }^{1}$ Md Shahidul Islam, ${ }^{2}$ Samir C. Majumdar, ${ }^{3}$ \\ Md Azizul Haque, ${ }^{4}$ Amzad Hossain Sardar ${ }^{5}$
}

\begin{abstract}
Chronic Obstructive Pulmonary Disease (COPD) is a major cause of chronic morbidity and mortality throughout the world. Many people suffer from this disease for many years and die prematurely from it or its complications. COPD is a preventable and treatable pulmonary disease. In early stage, diagnosis of COPD is difficult because sign \& symptoms are minimum. Only history of mild dyspnea, cough and/or sputum production or prolong smoking, exposure to occupational dusts or biomass fuels are present without any sign. Spirometry is the tool to diagnose COPD. If we can diagnose COPD in early stage then it is treatable and can prevent progression of the disease. Spirometry is a simple tool to diagnose COPD at any health care level. So this study was done to diagnose COPD in early stage among smokers.

This study was carried out in Department of Medicine (Indoor \& outdoor) of Rajshahi Medical College Hospital from March, 2010 to February, 2011. 255 smoker having exposure to $>10$ pack year smoking fulfilling inclusion and exclusion criteria were included and $\mathbf{3 0 0}$ apparently healthy non-smoker also were included as control. Both male \& female were included with age of the study population were from 30 years to 70 years. All of that study population was free from diseases which alter spirometric measurement. This exclusion was done by history, thorough clinical examination and relevant investigations. Among smokers, clinically $9(4.03 \%)$ were diagnosed to have COPD only and the spirometry also diagnosed these 9 smokers and other 32 smokers more to have COPD and thus diagnose 41(18.38\%) smokers to have COPD. The difference between clinical and spirometric diagnosis of COPD is statistically highly significant. The test done was Fisher's Exact Test, where $p$ value is $\mathbf{0 . 0 0 0}$.
\end{abstract}

So, spirometry is considered as a simple valuable instrument to diagnose COPD in early stage among smokers.

Key Word: Spirometry, COPD, Smoking

TAJ 2019; 32: No-1: 33-38

\section{Introduction}

Chronic Obstructive Pulmonary Disease (COPD) is a major cause of chronic morbidity and mortality throughout the world. Many people suffer from this disease for many years and die prematurely from it or its complications. Chronic
Obstructive Pulmonary Disease (COPD) is a common, preventable and treatable disease that is characterized by persistent respiratory symptoms and airflow limitation that is due to airway and/or alveolar abnormalities usually caused by significant exposure to noxious particles or gases. ${ }^{1}$

\footnotetext{
${ }^{1}$ Senior consultant, Gaibandha Sadar Hospital, Gaibandha.

${ }^{2}$ Assistant Professor, Department of Medicine, Rajshahi Medical College, Rajshahi.

${ }^{3}$ Associate Professor, Department of Respiratory Medicine, Rajshahi Medical College, Rajshahi.

${ }^{4}$ Associate Professor, Department of Medicine, Rajshahi Medical College, Rajshahi.

5 Junior Consultant, Upazilla Health Complex, Mohanpur.
} 
Among risk factors, tobacco smoking either active or passive, current or ex-smoking-all have a higher respiratory symptoms and lung function abnormalities, a greater annual rate of decline in FEV1 and a greater COPD mortality rate than nonsmokers. It is a major public health problem worldwide. Although prevalence vary across countries, it appreciably higher in smokers and exsmokers compared with non-smokers, in those older than 40 years compared with those younger than 40 years and in men compared with women. ${ }^{2}$ According to a study known as BOLD-BD (Burden of obstructed lung disease in Bangladesh), on COPD conducted by Bangladesh lung foundation, Burden of COPD in Bangladeshis are as follows ${ }^{3}$.

- Prevalence in $>40$ years of age is $21.24 \%$

- Prevalence in general population is $4.3 \%$

- $\quad$ Total burden of COPD patients is about 6 million $^{3}$ (BOLD-BD, 2007).

Initial diagnosis of COPD should be considered in any patient over age 40 years who has history of dyspnoea, chronic cough or sputum production and/or a history of exposure to risk factor and then confirmed by spirometry. ${ }^{5,6}$ Among investigationsspirometry, a critical tool to identify COPD in mild to moderate stage, is the gold standard, where forced vital capacity (FVC), forced expiratory volume in $1^{\text {st }}$ second (FEV1) and their ratio (FEV1/FVC) are determined and are expressed as percentage predicted value with reference to appropriate normal values as per age, sex, height, weight and race. Post bronchodilator value of FEV1/FVC $<70 \%$ or FEV1 $<80 \%$ predicted indicate COPD and thus diagnose COPD adequately and early.,3,4,6,7

Spirometric classification of COPD based on post bronchodilator FEV1 is done in the flowing way ${ }^{1}$
Stage I: Mild- $\quad$ FEV1/FVC $<0.70$

FEV1 $\geq 80 \%$ predicted

Stage II: $\quad$ FEV1/FVC $<0.70$

Moderate-

$50 \% \leq \mathrm{FEV} 1<80 \%$ predicted

Stage III: $\quad$ FEV1/FVC $<0.70$

Severe -

$30 \% \leq \mathrm{FEV} 1<50 \%$ predicted

Stage IV: Very $\quad$ FEV1/FVC $<0.70$

Severe -

FEV1 $<30 \%$ predicted or FEV1 $<50 \%$ predicted plus chronic respiratory failure.

Thus, history of key symptoms and exposure to risk factors combined with spirometry can help in early diagnosis of COPD.

\section{Materials and methods}

255 smoker having exposure to $>10$ pack year smoking fulfilling inclusion and exclusion criteria were included and 300 apparently healthy nonsmoker also were included as control. This study was carried out in Department of Medicine (indoor \& outdoor) of Rajshahi Medical College Hospital from March, 2010 to February, 2011. Both male \& female were included with age of the study population were from 30 years to 70 years. Patients having heart failure, respiratory failure, bronchiectasis, Tuberculosis, Asthma, malignant disease, CLD, CKD, Connective tissue diseases, DM, Obesity, Neuromuscular diseases were excluded. This exclusion was done by history, through clinical examination and relevant investigations. After providing informed consent, the patients underwent a physical examination and chest radiographies were provided. All (Smoker \& healthy nonsmoker) of that study sample were investigated by Desktop spirometer (Spirolab III MIR 980067REV1.9). The data were analyzed with the help of SPSS software program version16.0 descriptive analytical techniques involving frequency distribution computation of percentage, mean SD etc was applied. Association between variables was conducted applying chi-square and T test. p value $<0.05$ was considered as significant 


\section{Results}

Among smokers, clinically 9(4.03\%) were diagnosed to have COPD only and the spirometry also diagnosed these 9 smokers and other 32 smokers more to have COPD and thus diagnose 41(18.38\%) smokers to have COPD. The difference between clinical and spirometrically diagnosis of COPD is statistically highly significant. The test done was Fisher's Exact Test, where p value is 0.000.

Table 1: Number of clinically and spirometrically diagnosed COPD cases among smokers (n=223)

\begin{tabular}{lccccc} 
& & \multicolumn{2}{c}{ Clinical diagnosis } & & P value \\
& & Normal & COPD & Total & \\
\multirow{2}{*}{$\begin{array}{l}\text { Spirometric } \\
\text { diagnosis }\end{array}$} & Normal & 182 & 0 & 182 & \\
& COPD & 32 & 9 & 41 & 0.000 \\
& Total & 214 & 9 & 223 &
\end{tabular}

Among 300 non-smokers, no one had been diagnosed as COPD both clinically and spirometrically.

Table 2: Number of clinically and spirometrically diagnosed COPD cases among non-smokers

Spirometric diagnosis

$\begin{array}{lccc} & \text { Normal } & \text { COPD } & \text { Total } \\ \text { Normal } & 300 & 0 & 300 \\ \text { COPD } & 0 & 0 & 0 \\ \text { Total } & 300 & 0 & 300\end{array}$

The value of FEV1 of smokers and non-smokers people were 3.2301 and 3.3449 respectively and their standard deviation were 0.52207 and 0.44162 respectively. This difference in FEV1 value was statistically significant (p value 0.007).The value of FVC of smokers and non-smokers were 3.9857 and 4.0096 respectively and standard deviations were 1.47849 and 0.50218 respectively. This difference in FVC value was statistically not significant (p-value 0.794).The value of ratio of FEV1 and FVC among smokers and non-smokers were 79.42.06 and 79.8150 respectively and their standard deviations were 1.9145 and 1.68805 respectively. This difference of value of ratio of FEV1 and FVC among smokers and non-smokers were statistically significant (p-value 0.013).

Table 3: Spirometric values among smokers and non-smokers

$\begin{array}{lrcc}\text { Spirometric indices } & \text { Smoker(Mean } \pm \text { SD) } & \text { Non-smoker (Mean } \pm \text { SD) } & \text { P-value } \\ \text { FEV1 } & 3.2301 \pm 0.52207 & 3.3449 \pm 0.44162 & 0.007 \\ \text { FVC } & 3.9857 \pm 1.47849 & 4.0096 \pm 0.50218 & 0.794 \\ \text { FEV1/FVC } & 79.4206 \pm 1.91495 & 79.8150 \pm 1.68805 & 0.013\end{array}$

Out of 41 smokers diagnosed to have COPD, 22(53.65\%) had mild COPD, 10(24.39\%) had moderate COPD and 9(21.95\%) severe COPD. 
Table 4 a: Staging of clinically and spirometrically diagnosed COPD cases $(n=41)$

$\begin{array}{lcc}\text { Severity } & \text { Number } & \text { Percentage (\%) } \\ \text { Mild (FEV1/FVC }<0.7 \text {, FEV1 } \geq 80 \% \text { predicted). } & 22 & 53.66 \\ \text { Moderate (FEV1/FVC }<0.7 \text {, FEV1 50-<80\% predicted). } & 10 & 24.39 \\ \text { Severe (FEV1/FVC }<0.7 \text {, FEV1 } 30-<50 \% \text { predicted). } & 9 & 21.95 \\ \text { Total } & 41 & 100.00\end{array}$

Table 4 b: Staging of clinically and spirometrically diagnosed COPD cases $(n=41)$

$\begin{array}{lllll}\text { Diagnostic method } & \text { Mild } & \text { Moderate } & \text { Severe } & \text { Total } \\ \text { Clinical (followed by spirometry) }(\mathrm{n}=9) & - & - & 9 & 9 \\ \text { Spirometrically }(\mathrm{n}=32) & 22 & 10 & 0 & 32 \\ \text { Total } & 22 & 10 & 9 & 41\end{array}$

\section{Discussion}

In NICE study conducted by Yoshinosuke et al, in Japan, COPD is significantly more prevalent in older people. $3.5 \%$ in $40-49$ years old Vs. $24.4 \%$ in those $>70$ years of age and this increasing prevalence with increasing age is consistent with our study up to age of 60 years after which there was a decline in our study.

In BOLD-BD study, it has shown that about $80 \%$ smokers need to smoke only around 10 pack years to catch the disease and the study has considered this finding as more alarming than the international findings, where 20 pack-years are set as a bench mark in developing COPD. But our study showed that maximum number smokers with COPD 28(68.29\%) smoked $>20$ pack years where as the minimum numbers of smokers $13(31.7 \%)$ had smoked 10-20 pack years and finding was consistent with international finding.

In Bangladesh Lung Health Manual it has been shown that prevalence of COPD in Bangladesh in people $>40$ year of age is $21.24 \%$. Our study has shown $18.39 \%$ which was nearer to their finding. Younus $\mathrm{M}$ et al showed in their study in Lahore,
Pakistan, in 2008, showed that $18 \%$ smoker had physical sign of air flow limitation, which in our study was $4.05 \%$ (9) and on subsequent spirometry, 38\% smoker had COPD, 18\% mild COPD, $12 \%$ had moderate COPD, and $8 \%$ had severe COPD which in our study were $18.39 \%(41)$, 9.87\% (22), 4.48\%(10) and 4.05\% (9) respectively. As clinically $18 \%$ and spirometricaly $38 \%$ COPD cases were identified in their study and clinically $4.05 \%$ and spirometricaly $18.39 \%$ COPD cases were identified in our study, both studies had revealed that maximum number of COPD cases could be diagnosed spirometricaly. Again as maximum number of diagnosed COPD cases in both study were mild to moderate, $30 \%(18+12)$. in their study and $14.35 \%$ $(9.87+4.48)$ in our study so it could be concluded that spirometry can help in early diagnosis of COPD in smokers. Their study showed 38\% smoker had spirometric diagnosis of COPD among which $18 \%$ had mild COPD. $12 \%$ had moderate COPD, $8 \%$ had severe COPD according to Global initiative for chronic obstructive pulmonary disease severity criteria. Which in our study were 41(18.39\%), 22(53.66\%), 10(24.39\%) and 9(21.95\%) respectively. As clinicaly $18 \%$ and 
spirometricaly 38\%. COPD cases are diagnosed, so they conclude that spirometry helps for early diagnosis of COPD in smoker and can uncover a significant number of persons with sign of airflow limitation. In another similar study conducted by Qazi HA and et $\mathrm{al}^{5}$ in hydrabad, Pakistan in 2006, spirometric diagnosis of COPD, mild, moderate and severe COPD were 39\%, 19\%, 12\% and 8\% respectively which in our study were $41(18.39 \%)$, 22(53.66\%), $\quad 10(24.39 \%)$ and $9(21.95 \%)$ respectively. ${ }^{6} \quad$ So both study showed that maximum number of COPD cases could be identified by spirometry (39\% in their study and $18.39 \%$ (41) in our study) Again, as maximum number of diagnosed cases of COPD cases were mild to moderate, $31 \%(19+12)$ in their study and $14.35 \%(9.87+4.48)$ in our study. So it could be concluded that spirometry helps in early diagnosis of COPD.

In another study conducted by David Stav MD and Meir Raz MD in Israel showed that only 4\% had been diagnosed as COPD prior to spirometry and after spirometry $22 \%$ of the smokers were diagnosed as COPD. ${ }^{7}$ These results were consistent with those found in our study because in our study,, 4.05\%(9) were diagnosed COPD prior to spirometry and after spirometry, $18.39 \%$ (41) of smokers were diagnosed as COPD. So, both the studies showed that maximum number of COPD cases could be detected by spirometry. Again as maximum number of diagnosed COPD cases were mild to moderate, $200(50+50)$ out of 232 in their study and $32(22+10)$ out of 41 in our study. So, it could be concluded that spirometry can help in early diagnosis of COPD among smokers. In NICE study Fukuchi Y et al used Spirometry and found that prevalence of airflow limitation in Japan was higher than previously reported, suggesting a high degree of under recognition of COPD and highlighting the need for enhanced screening with spirometry and thus supports our study. ${ }^{8}$

Ulrik CS et $\mathrm{al}^{9}$ showed in their study that among the most common respiratory symptoms, cough, sputum and dyspnoea were present in 63\%, 21\% and $66 \%$ respectively of study population and that air way obstruction was found in $34.8 \% .{ }^{9}$ In our study cough, sputum and dyspnoea were present in $94.6 \%, 34.5 \%$ and $5.4 \%$ people respectively and COPD in $18.39 \%$. They also found that $79 \%$ of subjects with air way obstruction had mild to moderate COPD which in our study was $78.05 \%$. As they conclude that early detection of COPD is feasible by offering spirometry to individuals with relevant exposure so they are favouring our study in early detection of COPD among smokers with spirometry.

Vandevoordea $\mathrm{J}$ et $\mathrm{al}^{10}$ in their study in Belgium shown that (17.1\% people had already established COPD). Screening by spirometry revealed $46.6 \%$ prevalence of COPD in current smokers smoked at least 15 pack years between 40-70 years of age and under diagnosis of COPD was more frequent in younger age group (40-49 yrs, 50-59 yrs). Sampling criteria in our study are almost similar. Spirometry has revealed COPD in $18.39 \%$ and under diagnosed cases were also more frequent among younger age group (30-40 yrs, 41-50 yrs, 51-60 yrs) total 28(68.29\%). So spirometry, can help in early diagnosis COPD among smokers.

Schimhofer $\mathrm{L}$ et $\mathrm{al}^{11}$ in their study on COPD prevalence in salzburg, Austria by spirometry among smokers, aged $\geq 40$ yrs of age with respiratory symptoms, have shown that doctors diagnosis of COPD was reported only in $5.6 \%$ of participants which may be equivalent to our clinically diagnosed case $9(4.04 \%)$. In their study stage I prevalence was $26.1 \%$ stage II prevalence was $10.7 \%$ which in our study were $22(9.87 \%)$ and $10(4.48 \%)$ respectively. Thus our study had carried a good validity in favour of early diagnosis COPD smokers with spirometry.

\section{Conclusion}

A significant number of people aged 40 years or more who have smoked $>10$ pack years suffer from COPD though they are unaware of their disease and their disease can be identified by spirometry.

\section{Recommendation:}

Further larger scale study may be conducted. Spirometry should be done at all health care facilities for patients suspected to have COPD who are aged 40 or more years and have smoked $>10$ 
pack year for early detection of COPD among them.

\section{References}

1. GOLD (Global Initiative for chronic obstructive lung disease) executive summary. Global strategy for Diagnosis, Management and prevention of COPD, updated 2017.

2. Menezes AM, Perez-Padilla R, Jardim JR, Maino. A, Lopez MV, Valdivin G, Montesde Oca M, Talamo C, Hallal PC, Victora CG. Chronic obstructive pulmonary disease in five Latin American cities. (The PLATINO study): a prevalence study Lancet 2005; 366: 1875-1881.

3. Burden of Obstructive Lung Disease in Bangladesh (BOLD-BD conducted by BANGLADESH LUNG FOUNDATION, Report on National COPD study, 2007.

4. Bangladesh lung health manual October 2010; Vol2: P 6.

5. Younus M, Mehmood A, Rasul S et al. Role of spirometry in the diagnosis of chronic obstructive pulmonary disease in smokers. J Allama Iqbal Med Coll Dec 2009; 7(4): 11-9.
6. Aliqazi $H$, Soomro $J A$, Kalisarsoomro $T$ et al. Spirometric screening of chronic obstructive pulmonary disease in smokers presenting to tertiary care centre. J Medicine 2009; 10: 40-44.

7. Stav $D$ and Raz M. Prevalence of chronic obstructive pulmonary disease among smokers aged 45 and up in Israel. IMAJ 2007; 9: 800-801.

8. Fukuchi $Y$, Nishimura $M$, Ichinose $M$ et al. OPD in Japan: the Nippon COPD Epidemiology study. Respirology 2004; 9(4) 458-465.

9. Ulrik CS, Kokke A, Dahl R et al. Early detection of COPD in general practice. International Journal of Chronic Obstructive Pulmonary Disease 2011;6: 123-127.

10. Vandevoordea J, Verbanckb S, Gijsselsa L et al. Early detection of COPD: A case finding study in general practice Purchase. Respiratory Medicine 2007; 1: 525-530.

11. Schimhofer L, Lamprecht B, Vollmer WM et al. COPD prevalence in salzburg, Austria: Results from the burden of obstructive lung disease (BOLD) study. Chest 2007; 131: 29-36. 